\title{
Sulforaphane enhances apoptosis induced by Lactobacillus pentosus strain S-PT84 via the TNF $\alpha$ pathway in human colon cancer cells
}

\author{
SHUSUKE YASUDA*, MANO HORINAKA* ${ }^{*}$ and TOSHIYUKI SAKAI \\ Department of Molecular-Targeting Cancer Prevention, Graduate School of Medical Science, \\ Kyoto Prefectural University of Medicine, Kyoto, Kyoto 602-8566, Japan
}

Received August 29, 2018; Accepted May 29, 2019

DOI: 10.3892/ol.2019.10739

\begin{abstract}
Sulforaphane and Lactobacilli induce apoptosis in several cancer cells. Sulforaphane, a dietary isothiocyanate, is an attractive agent due to its potent anticancer effects. Sulforaphane suppresses the proliferation of various cancer cells in vitro and in vivo. The present study investigated the effect of sulforaphane and a co-culture with Lactobacillus-treated peripheral blood mononuclear cells (PBMCs) in human colon cancer cells. The combination markedly induced apoptosis in human colon cancer HCT116 and SW480 cells. A pan-caspase inhibitor markedly inhibited apoptosis, and a tumor necrosis factor (TNF) receptor/Fc chimera partially inhibited apoptosis in both cells. The amount of TNF $\alpha$ secretion in the culture supernatant was significantly increased by co-culture with Lactobacillus-treated normal human PBMCs. On the other hand, the expression of cellular inhibitor of apoptosis-2 (cIAP-2), an anti-apoptotic protein, was increased by co-culture with Lactobacillus-treated PBMCs in colon cancer cells, but sulforaphane treatment significantly suppressed the induction of cIAP-2. The present results revealed that sulforaphane enhances apoptosis in human colon cancer cells under co-culture with Lactobacillus-treated PBMCs via the TNF $\alpha$ signaling pathway.
\end{abstract}

\section{Introduction}

Malignant tumors are a serious disease and since 1981 have the highest risk of death in Japan. In particular, colon cancer

Correspondence to: Dr Mano Horinaka, Department of Molecular-Targeting Cancer Prevention, Graduate School of Medical Science, Kyoto Prefectural University of Medicine, 465 Kajii-cho, Kawaramachi-Hirokoji, Kamigyo-ku, Kyoto, Kyoto 602-8566, Japan E-mail: m-hori@koto.kpu-m.ac.jp

*Contributed equally

Abbreviations: PBMCs, peripheral blood mononuclear cells; TNF, tumor necrosis factor

Key words: sulforaphane, Lactobacillus, tumor necrosis factor $\alpha$, apoptosis, colon cancer is the second most common type of cancer death (1). The association between fruit and vegetable intake and colorectal cancer risk has been investigated by many epidemiologic studies (2-4). Fruit and vegetables contain cancer-preventive agents, and dietary chemoprevention strategies have gained significant interest (5-7).

Sulforaphane is an isothiocyanate that is abundant in cruciferous vegetables, including broccoli sprouts, cabbage, and cauliflower $(8,9)$. Several reports showed that sulforaphane, a well-known phytochemical, induces cell cycle arrest and apoptosis in cancer cells (10-14). Sulforaphane is a promising compound for cancer prevention and therapy (15-18). Sulforaphane downregulates the expression of Bcl-2, inhibitor of apoptosis (cIAP)-1/2, and XIAP in prostate cancer (14) and the expression of Bcl-2 family proteins in human hepatoma cells (19).

There are several reports that suggest that Lactobacilli have antiumor activity. Takeda et al (20) found that drinking fermented products containing Lactobacilli have immunological effects on the immune system of healthy individuals, and Lactobacilli have anticancer effects in vitro and in vivo (21-23). Ishikawa et al (24) found in randomized clinical studies that a Lactobacillus strain prevents colorectal tumors. Lactobacillus strains induce tumor necrosis factor-related apoptosis-inducing ligand (TRAIL), tumor necrosis factor (TNF) $\alpha$, interleukin (IL)-1 $\beta$, and IL-10 from normal human peripheral blood mononuclear cells (PBMCs) (25-27).

Izumo et al $(28,29)$ and Hayama et al $(30)$ reported that the Lactobacillus (L.) pentosus strain S-PT84, isolated from Kyoto pickles, has inhibitory activity against influenza virus, Salmonella Typhimurium, and Candida albicans infection in mice, and S-PT84 enhances IFN- $\alpha$ production from plasmacytoid dendritic cells by virus stimulation (31).

Previously, we proposed 'combination-oriented moleculartargeting prevention' of cancer (32). A combination of two agents can synergistically enhance their preventive effects, even if the effect of each single agent is weak. A combination of sulforaphane and curcumin has a synergistic anti-inflammatory effect (33), and a combination of sulforaphane and epigallocatechin-gallate has a synergistic growth-inhibitory effect in human colon carcinoma cells (34). Additionally, sulforaphane enhances TRAIL-induced 
apoptosis in human cancer cells $(35,36)$. TRAIL is a member of the TNF family of cytokines, which is crucial for cancer prevention.

Therefore, we hypothesized that the combination of sulforaphane and a TRAIL inducer, such as Lactobacillus, may have a beneficial effect for cancer prevention. In this study, we evaluated the effect of a combination of sulforaphane and co-culture with L. pentosus S-PT84-treated PBMCs in human colon cancer cells.

\section{Materials and methods}

Reagents and antibodies. Sulforaphane was purchased from LKT Laboratories (St. Paul, MN, USA) and dissolved in dimethyl sulfoxide (DMSO). Lactobacillus pentosus strain S-PT84 was kindly gifted from the Suntory Global Innovation Center (Kyoto, Japan) (37). Heat-killed L.pentosus S-PT84 was freeze-dried and used for the following experiments: Propidium iodide was purchased from Sigma (St. Louis, MO, USA). 5, 5', 6, 6'-tetrachloro-1, 1', 3, 3'-tetraethylbenzimidazolylcarbocyanine iodide (JC-1) was purchased from FUJIFILM Wako pure chemical corporation (Osaka, Japan). Annexin V-FITC apoptosis detection kit was purchased from Nacalai Tesque (Kyoto, Japan). Antibodies against cIAP-1, cIAP-2, Bcl-xL, acetylated-Histone $\mathrm{H} 4$, and Histone $\mathrm{H} 4$ were obtained from Cell Signaling Technology (Danvers, MA, USA). Antibody against TNFR1 was purchased from Santa Cruz Biotechnology (Santa Cruz, CA, USA). Antibodies against Bcl-2 and Bim were purchased from Abcam (Cambridge, MA, USA). Antibody against Bax was purchased from BD Biosciences (San Jose, CA, USA). Antibody against GAPDH was purchased from HyTest (Turku, Finland). Antibodies against XIAP, human recombinant $\mathrm{TNF} \alpha / \mathrm{Fc}$ chimera, human recombinant DR5/Fc chimera, human recombinant Fas/Fc chimera, and zVAD-fmk were obtained from R\&D Systems (Minneapolis, MN, USA). Granzyme B inhibitor I was obtained from Calbiochem (San Diego, CA, USA). HRP-conjugated anti-mouse IgG and HRP-conjugated anti-rabbit IgG were purchased from GE Healthcare (Piscataway, NJ, USA).

Cell culture. Human colon cancer HCT116 and SW480 cells and normal human colon epithelial CCD 841 CoN cells were obtained from the American Type Culture Collection (Rockville, MD, USA). HCT116 and SW480 cells were maintained in Dulbecco's modified Eagle's medium supplemented with $10 \%(\mathrm{v} / \mathrm{v})$ fetal bovine serum, $4 \mathrm{mmol} / 1$ glutamine, $50 \mathrm{U} /$ $\mathrm{ml}$ of penicillin $\mathrm{G}$, and $100 \mu \mathrm{g} / \mathrm{ml}$ of streptomycin. CCD 841 CoN cells were maintained in Eagle's minimum essential medium supplemented with $10 \%$ (v/v) fetal bovine serum, $4 \mathrm{mmol} / \mathrm{l}$ glutamine, $50 \mathrm{U} / \mathrm{ml}$ of penicillin $\mathrm{G}$, and $100 \mu \mathrm{g} / \mathrm{ml}$ of streptomycin. Normal human PBMCs were isolated as previously described (25). All cells were incubated at $37^{\circ} \mathrm{C}$ in a humidified atmosphere containing $5 \% \mathrm{CO}_{2}$.

For co-culture, HCT116 or SW480 cells were seeded onto 12-well plates (BD Falcon, no. 353503). The next day, PBMCs were seeded on cell culture inserts $(0.4 \mu \mathrm{m}$ pores; BD Falcon no. 353494 ) in a 12 -well plate.

Cell proliferation assay. The number of viable cells was determined using the Cell Counting Kit- 8 according to the manufacturer's instructions (Dojindo Molecular Technology, Kumamoto, Japan).

Detection of sub-G1 population. Cells were stained with $10 \mu \mathrm{g} / \mathrm{ml}$ of propidium iodide. Flow cytometry was performed with FACSCalibur (BD Biosciences, Franklin Lakes, NJ, USA) and CellQuest software (BD Biosciences).

Detection of apoptosis (JC-1). Cells were stained with $2 \mu \mathrm{mol} / 1$ JC-1 and incubated for $15 \mathrm{~min}$. Cells were washed twice and resuspended with PBS. Flow cytometry was performed with FACSCalibur and CellQuest software.

Detection of apoptosis (Annexin V). Annexin V-FITC apoptosis detection kit was used according to the manufacturer's protocol. Briefly, cells were resuspended with Annexin V binding buffer and incubated with Annexin $\mathrm{V}$ and propidium iodide for $15 \mathrm{~min}$. Flow cytometry was performed with FACSCalibur and CellQuest software.

Enzyme-linked immunosorbent assay (ELISA). Cells were centrifuged and the supernatant was collected. A human TNF $\alpha$ ELISA kit (Abcam, Cambridge, UK) was used according to the manufacturer's instructions.

Western blotting. Cells were lysed in buffer containing $50 \mathrm{mmol} / 1$ Tris- $\mathrm{HCl}$ ( $\mathrm{pH} 7.5$ ), 1\% SDS, $2 \mu \mathrm{g} / \mathrm{ml}$ leupeptin, $2 \mu \mathrm{g} / \mathrm{ml}$ aprotinin, and $1 \mathrm{mmol} / 1$ dithiothreitol (DTT). The lysate was sonicated and centrifuged at 14,000 $\mathrm{g}$ for $20 \mathrm{~min}$ at $4^{\circ} \mathrm{C}$, and the supernatant was collected. Equal amounts of lysate were analyzed by SDS-PAGE and transferred to PVDF membranes (Millipore, Bedford, MA, USA). The blots were blocked in blocking buffer for $1 \mathrm{~h}$ at room temperature and incubated with the appropriate primary antibody in blocking buffer for $1 \mathrm{~h}$ at room temperature. The blots were then washed and incubated with the appropriate horseradish peroxidase-conjugated secondary antibody for $1 \mathrm{~h}$, and signals were detected using a Chemilumi-one chemiluminescent kit (Nacalai Tesque, Kyoto, Japan) or Immobilon Western Chemiluminescent HRP Substrate (Millipore). The band intensities were quantified by ImageJ software (NIH).

Statistical analysis. Data are the means \pm standard deviation of three experiments. For simple group means analysis, data were analyzed using a Student's t-test and differences were considered significant at $\mathrm{P}<0.05$. For between-group comparisons, one-way ANOVA and Tukey's post hoc test were performed using Microsoft Excel 2007 (Microsoft Corporation). $\mathrm{P}<0.05$ was considered to indicate a statistically significant difference.

\section{Results}

Sulforaphane enhances apoptosis induced by co-culture with Lactobacillus-treated PBMCs in human colon cancer cells. Sulforaphane, a well-known phytochemical, induces apoptosis in cancer cells (10-14). We investigated the effect of sulforaphane on cell growth in human colon cancer HCT116 and SW480 cells and found that sulforaphane suppressed the growth of both cells in a dose-dependent manner (Fig. 1A). 

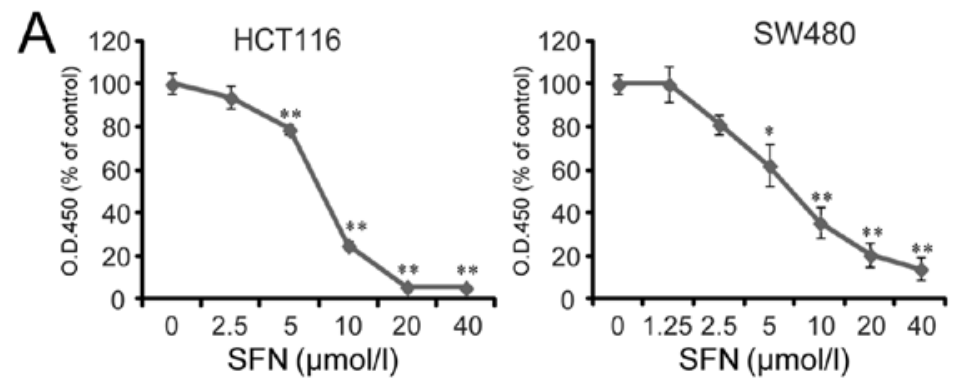

B
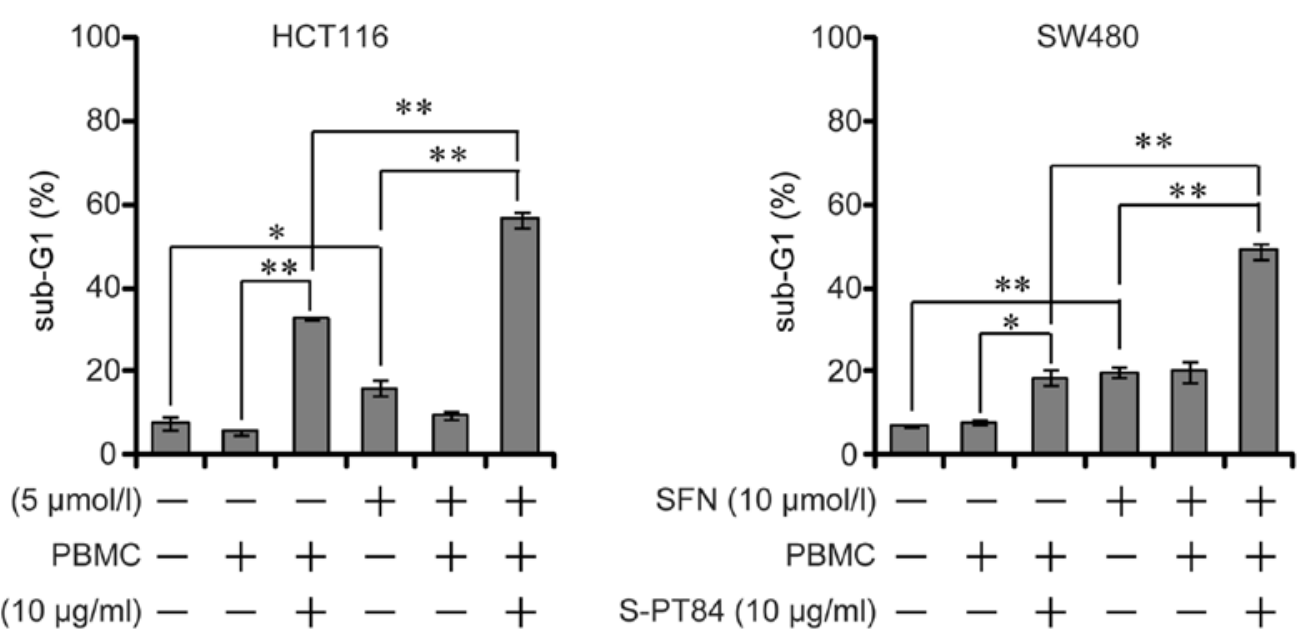

S-PT84 $(10 \mu \mathrm{g} / \mathrm{ml})--+-\quad+\quad+$ S-PT84 $(10 \mu \mathrm{g} / \mathrm{ml})--+$

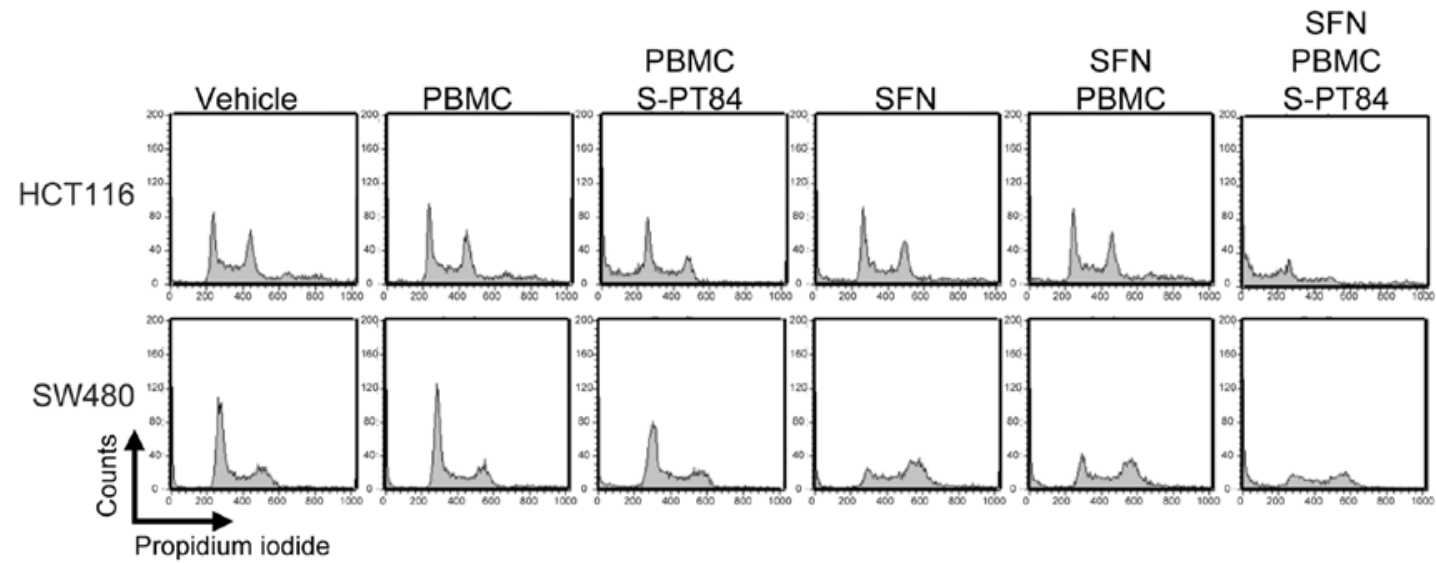

Figure 1. SFN enhances apoptosis induced by Lactobacillus in human colon cancer cells. (A) Cell proliferation assay. HCT116 and SW480 cells were treated with SFN at various concentrations for $72 \mathrm{~h}$, and cell growth was determined using Cell Counting Kit- 8 . ${ }^{*} \mathrm{P}<0.05$ and ${ }^{* * *} \mathrm{P}<0.01 \mathrm{vs}$. $0 \mu \mathrm{mol} / 1 \mathrm{SFN}$. (B) Detection of sub-G1 population cells. PBMCs were pre-incubated with $10 \mu \mathrm{g} / \mathrm{ml}$ L. pentosus S-PT84 for $24 \mathrm{~h}$. HCT116 or SW480 cells were co-incubated with PBMCs $(\mathrm{E} / \mathrm{T}$ ratio=100:1), incubated with or without SFN for $48 \mathrm{~h}$, and then harvested. After fixation and staining with propidium iodide, HCT116 and SW480 cells were subjected to cell cycle analysis using FACSCalibur. Representative histogram patterns from HCT116 and SW480 cells. Data are presented as the mean \pm standard deviation of three experiments. ${ }^{*} \mathrm{P}<0.05$ and ${ }^{* *} \mathrm{P}<0.01$, as indicated. SFN, Sulforaphane; PBMCs, peripheral blood mononuclear cells.

Previously, we showed that Lactobacillus strains facilitated natural killer activity against human cancer cells in vitro (25). Here, we evaluated the effect of L. pentosus S-PT84 on cellular immunity by inducing apoptosis in human colon cancer HCT116 and SW480 cells in co-culture with PBMCs treated by L. pentosus S-PT84. First, isolated PBMCs from a healthy volunteer were pre-treated by L. pentosus S-PT84 for $24 \mathrm{~h}$. Second, PBMCs were co-cultured with human colon cancer cells. After $48 \mathrm{~h}$, the sub-G1 population was examined by flow cytometry. Although non-treated PBMCs showed basal levels of cytotoxicity, Lactobacillus-treated PBMCs induced apoptosis against HCT116 and SW480 cells (Fig. 1). Similarly, the sub-G1 population was significantly increased by sulforaphane in both human colon cancer cell lines tested (Fig. 1B).

We evaluated the effect of the combination of sulforaphane and co-culture with Lactobacillus-treated PBMCs in human colon cancer cells. As shown in Fig. 1B, the addition of sulforaphane increased the sub-G1 population from 33 to $57 \%$ in HCT116 cells and from 19 to $49 \%$ in SW480 cells under co-culture with Lactobacillus-treated PBMCs. Next, Annexin V/propidium iodide staining was used to analyze apoptosis by treatment in human colon cancer HCT116 and SW480 cells or in normal human colon CCD $841 \mathrm{CoN}$ cells. Sulforaphane markedly enhanced apoptosis induced by co-culture with Lactobacillus-treated PBMCs in human 
A

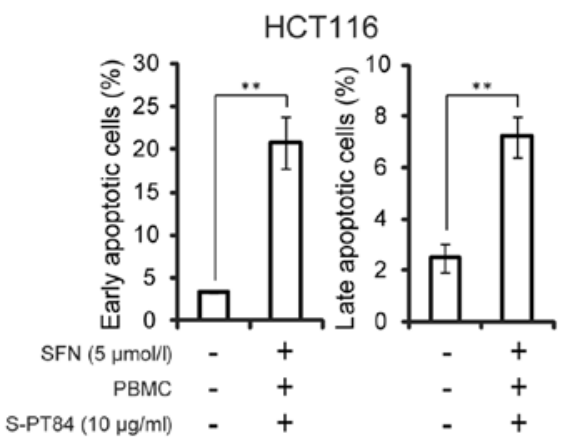

HCT116
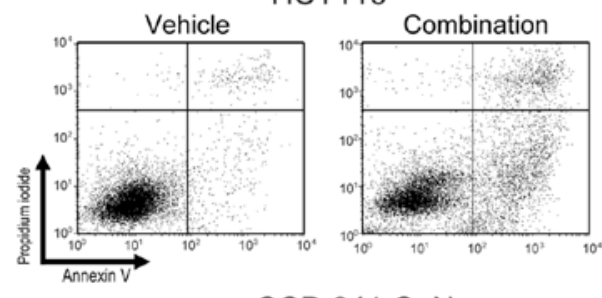

CCD $841 \mathrm{CoN}$
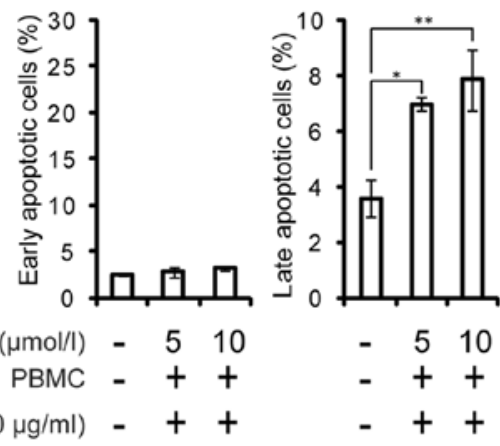

B

$\operatorname{SFN}(\mu \mathrm{mol} / \mathrm{l}) \quad-510$

PBMC - ++

S-PT84 $(10 \mu \mathrm{g} / \mathrm{ml})-\quad+\quad+$

HCT116

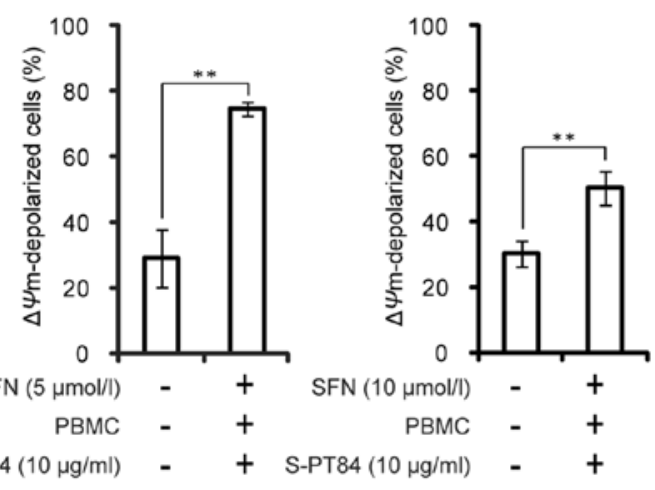

SW480

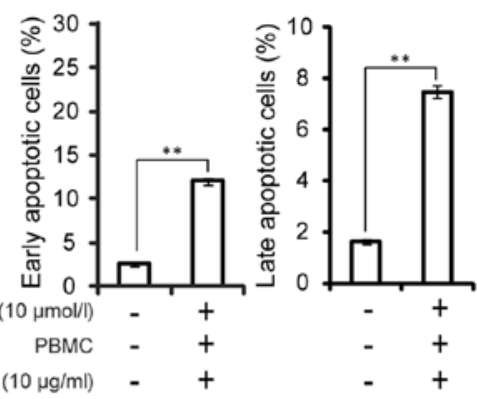

SW480
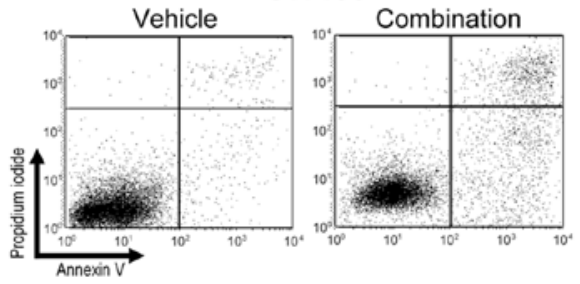

CCD $841 \mathrm{CoN}$

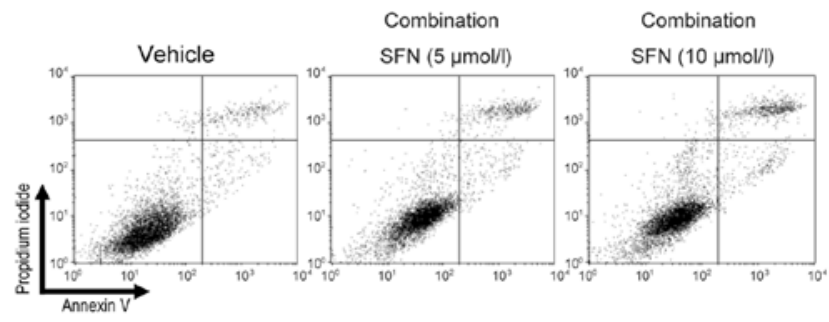

HCT116
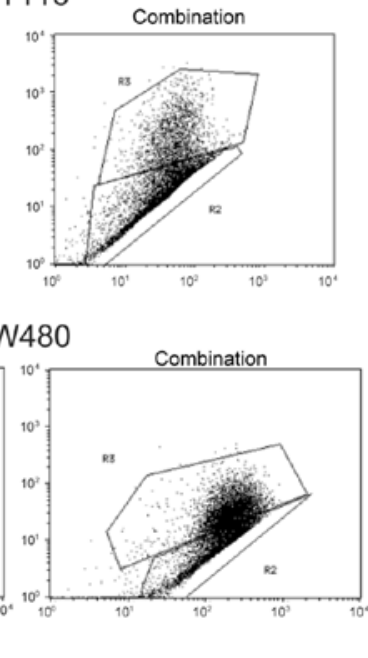

Figure 2. SFN enhances apoptosis induced by Lactobacillus in human colon cancer cells. (A) Annexin V and propidium iodide staining. PBMCs were pre-incubated with $10 \mu \mathrm{g} / \mathrm{ml}$ L. pentosus S-PT84 for $24 \mathrm{~h}$. HCT116, SW480, or CCD 841 CoN cells were co-incubated with PBMCs (E/T ratio=100:1), incubated with SFN for $48 \mathrm{~h}$, and then harvested. After staining with Annexin V and propidium iodide, the cells were subjected to apoptosis analysis using FACSCalibur. The bottom right quadrant indicates early apoptotic cells, whereas the top right quadrant indicates late apoptotic cells. (B) JC-1 staining to measure mitochondrial depolarization. HCT116 or SW480 cells were co-incubated with PBMCs (E/T ratio=100:1), incubated with SFN for 48 h, and then harvested. PBMCs were pre-incubated with $10 \mu \mathrm{g} / \mathrm{ml}$ L. pentosus S-PT84 for $24 \mathrm{~h}$. After staining with JC-1, the cells were subjected to apoptosis analysis using FACSCalibur. The top gate indicates normal mitochondria (healthy cells, red fluorescence), whereas the bottom gate indicates depolarized mitochondria (apoptotic cells, green fluorescence). Data are presented as the mean \pm standard deviation of three experiments. ${ }^{*} \mathrm{P}<0.05$ and ${ }^{* *} \mathrm{P}<0.01$, as indicated. SFN, Sulforaphane; PBMCs, peripheral blood mononuclear cells.

colon cancer cells more than in normal human colon cells (Fig. 2A). In addition, we used PBMCs from another volunteer to assess the combination of sulforaphane and L. pentosus
S-PT84-treated PBMCs (Fig. S1). As a result, the combination also induced apoptosis in HCT116 cells markedly. Furthermore, we assessed the mitochondrial transmembrane 
potential in human colon cancer HCT116 and SW480 cells by JC-1 staining (Fig. 2B). To investigate the mitochondria membrane potential $(\Delta \Psi \mathrm{m})$ involved in apoptotic induction, we analyzed apoptosis using a mitochondria-specific dye JC-1. As shown in Fig. 2B, the combination of sulforaphane and co-culture with Lactobacillus-treated PBMCs markedly decreased $\Delta \Psi \mathrm{m}$ in human colon cancer HCT116 and SW480 cells, which indicates an increase in apoptosis.

Sulforaphane enhances apoptosis induced by Lactobacillus in human colon cancer cells via the TNF $\alpha$ pathway. Three death factors (TNFo, FasL, and TRAIL) and their receptors have been identified (38). Furthermore, cytotoxic lymphocytes induce apoptosis in target cells by these death factors and/or perforin and granzyme B $(39,40)$. To investigate the apoptosis pathway induced by sulforaphane and co-culture with Lactobacillus-treated PBMCs, we used a TNFR/Fc chimera, DR5/Fc chimera, Fas/Fc chimera, Granzyme B inhibitor I, and pan-caspase inhibitor. Apoptosis was markedly blocked by the pan-caspase inhibitor zVAD-fmk, which indicates that apoptosis was caspase-dependent in HCT116 and SW480 cells (Fig. 3). Furthermore, the TNFR/Fc chimera partially inhibited apoptosis in both cells (Fig. 3). On the other hand, the DR5/Fc chimera, Fas/Fc chimera, and Granzyme B inhibitor I did not affect apoptosis. These results suggest that the combination of sulforaphane and co-culture with Lactobacillus-treated PBMCs induced caspase-dependent apoptosis by the TNF $\alpha$-TNFR pathway.

Secretion of TNF $\alpha$ is increased by addition of Lactobacillus. We found that TNF $\alpha$ was involved in apoptosis by a combination of sulforaphane and co-culture with Lactobacillus-treated PBMCs. Microbial stimuli increases the secretion of various cytokines, including TNFa, from PBMCs (26). Therefore, we evaluated the amount of TNF $\alpha$ secretion from the combination of sulforaphane and co-culture with Lactobacillus-treated PBMCs using culture supernatant by ELISA. As shown in Fig. 4, TNF $\alpha$ concentration markedly increased by co-culture with Lactobacillus-treated PBMCs, regardless of sulforaphane treatment, in both cells.

Effects of sulforaphane and/or co-culture with Lactobacillustreated PBMCs on the expression of various intracellular regulators of apoptosis on human colon cancer cells. To investigate the extrinsic and intrinsic pathways of apoptosis induced by the combination of sulforaphane and co-culture with Lactobacillus-treated PBMCs, we examined the expression of apoptosis-related proteins using western blotting (Fig. 5), and normalized histograms were shown in Fig. S2. As shown in these data, cIAP-1 and cIAP-2, anti-apoptotic IAP family proteins, were significantly upregulated by co-culture with Lactobacillus-treated PBMCs in both cancer cells. However, sulforaphane treatment suppressed the induction of cIAP-1 and cIAP-2 (Figs. 5A, B and S2). Co-culture with Lactobacillus-treated PBMCs slightly induced the expression of TNFR1, a TNF $\alpha$ receptor, in HCT116 cells (Figs. 5A and S2). Additionally, sulforaphane further increased the induction of TNFR1 in HCT116 cells (Figs. 5A, B and S2). XIAP was markedly downregulated by sulforaphane in SW480 cells with or without co-culture with Lactobacillus-treated
A

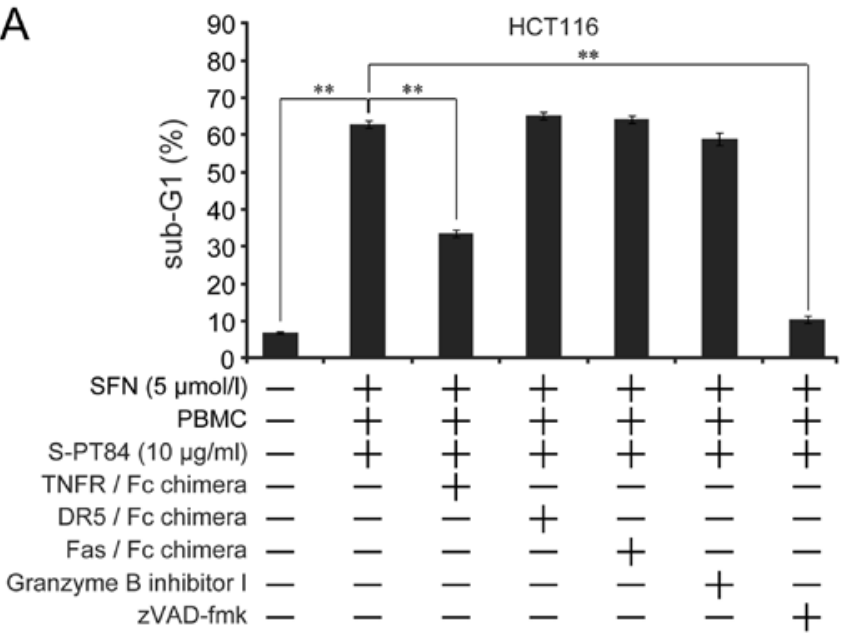

B

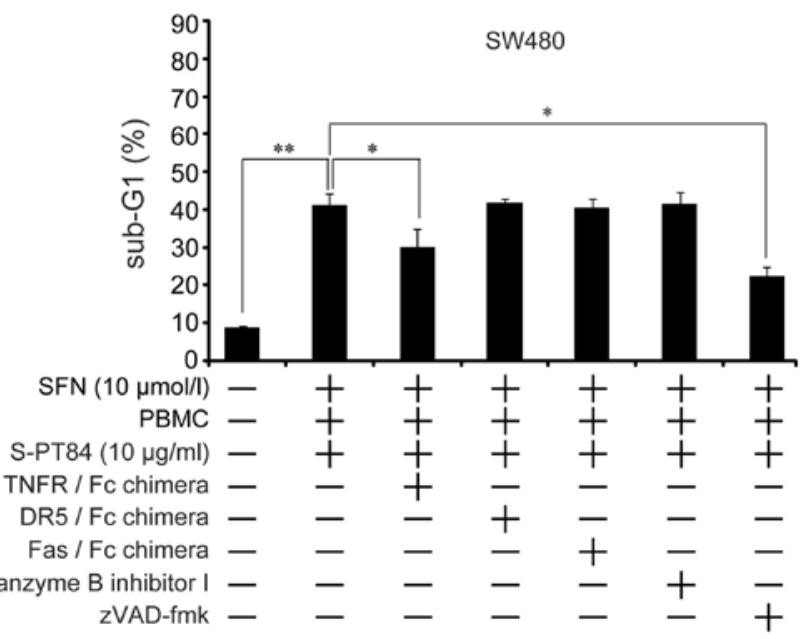

Figure 3. SFN enhances apoptosis induced by Lactobacillus in human colon cancer cells via the TNF $\alpha$ pathway. PBMC $\left(2 \times 10^{6} / \mathrm{ml}\right)$ were pre-incubated with $10 \mu \mathrm{g} / \mathrm{ml} \mathrm{L}$. pentosus S-PT84 for $24 \mathrm{~h}$. HCT116 and SW480 cells were co-incubated with PBMCs under treatment of SFN with or without $1 \mu \mathrm{g} / \mathrm{ml} \mathrm{TNFR} / \mathrm{Fc}$ chimera, $1 \mu \mathrm{g} / \mathrm{ml} \mathrm{DR5/Fc} \mathrm{chimera,} 1 \mu \mathrm{g} / \mathrm{ml} \mathrm{Fas} / \mathrm{Fc}$ chimera, $20 \mu \mathrm{mol} / 1$ Granzyme B inhibitor I, or $20 \mu \mathrm{mol} / 1 \mathrm{zVAD}-\mathrm{fmk}$ for $48 \mathrm{~h}$, and then harvested. After fixation and staining with propidium iodide, (A) HCT116 or (B) SW480 cells were subjected to cell cycle analysis using FACSCalibur. Data are presented as the mean \pm standard deviation of three experiments. ${ }^{*} \mathrm{P}<0.05$ and ${ }^{* *} \mathrm{P}<0.01$, as indicated. SFN, Sulforaphane; PBMC, peripheral blood mononuclear cells; TNFR, tumor necrosis factor receptor.

PBMCs (Figs. 5B and S2). The expression of Bcl-2 was slightly induced by sulforaphane with Lactobacillus-treated PBMCs in HCT116 cells (Figs. 5A and S2). Co-culture with Lactobacillus-treated PBMCs increased Bax in SW480 cells with or without sulforaphane treatment (Figs. 5B and S2). The expression of Bim, Bcl-xL and Bcl-2 did not significantly change in SW480 cells (Figs. 5B and S2). These results raise the possibility that TNFR1 in the extrinsic pathway and cIAP-1, cIAP-2 and Bax in the intrinsic pathway were involved in apoptosis by the combination of sulforaphane and co-culture with Lactobacillus-treated PBMCs in human colon cancer cells.

\section{Discussion}

Combinations of different chemopreventive agents may synergistically enhance their preventive effects, and 'combination-oriented molecular-targeting prevention' of cancer 

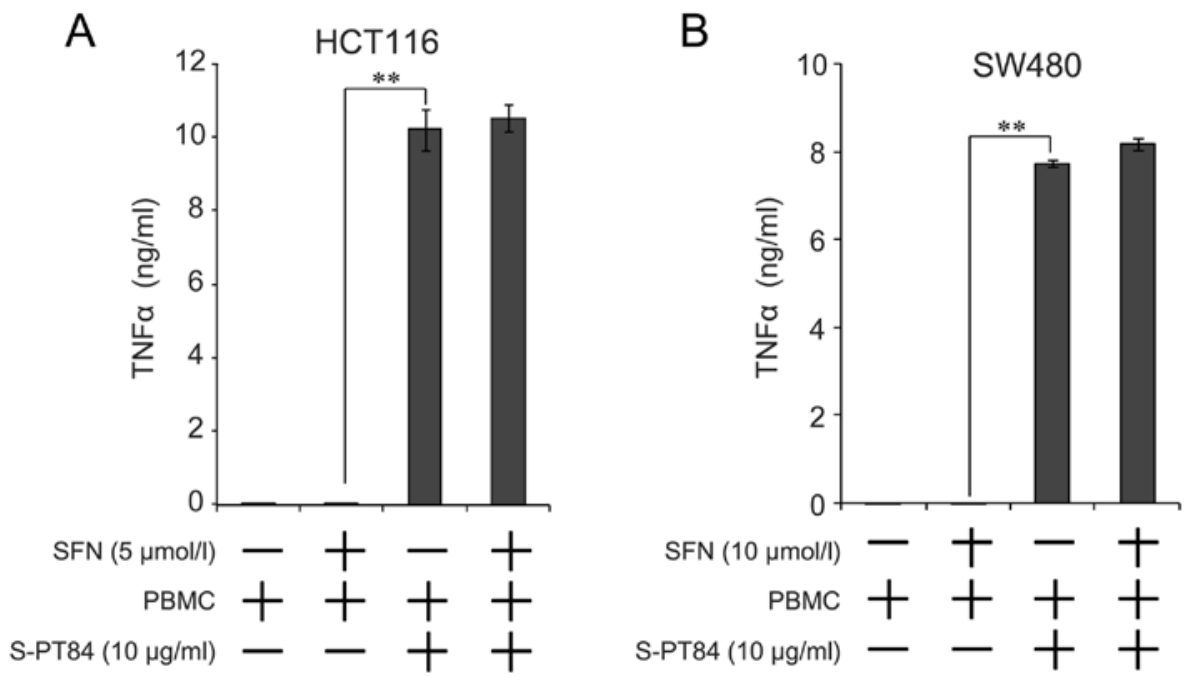

Figure 4. Secretion of TNFa is increased in PBMCs stimulated with Lactobacillus. PBMCs $\left(2 \times 10^{6} / \mathrm{ml}\right)$ were pre-incubated with $10 \mu \mathrm{g} / \mathrm{ml}$ L.pentosus S-PT84 for $24 \mathrm{~h}$. (A) HCT116 or (B) SW480 cells were co-incubated with PBMCs under SFN treatment for $48 \mathrm{~h}$, and the culture supernatant was collected. Concentrations of TNF $\alpha$ in the culture supernatant were measured by ELISA. Data are presented as the mean \pm standard deviation of three experiments. ${ }^{* *} \mathrm{P}<0.01$, as indicated. SFN, Sulforaphane; PBMCs, peripheral blood mononuclear cells; TNF $\alpha$, tumor necrosis factor.
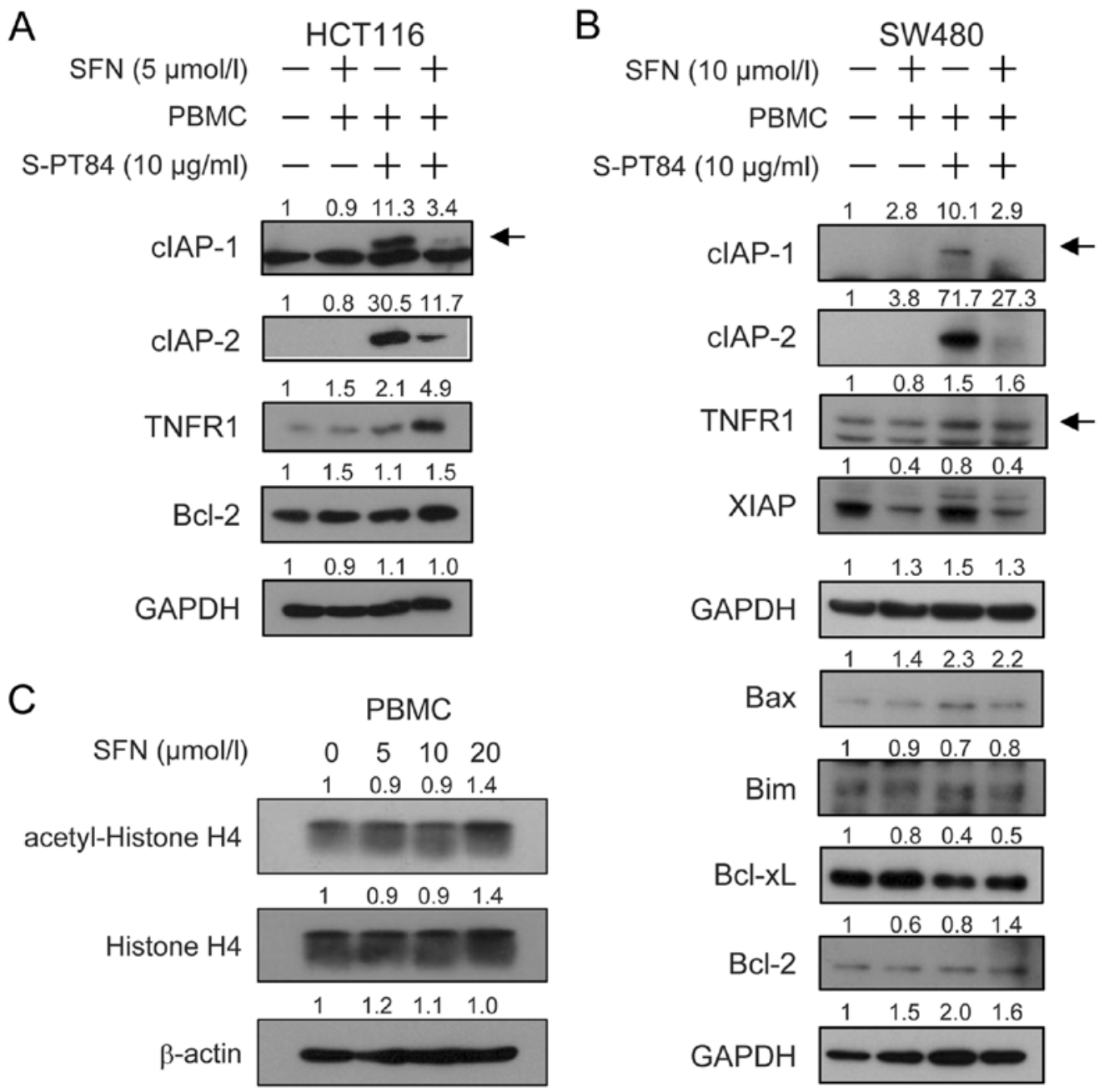

Figure 5. Effects of SFN and/or PBMCs stimulated with Lactobacillus on the expression of various intracellular regulators of apoptosis on human colon cancer cells. PBMCs $\left(2 \times 10^{6} / \mathrm{ml}\right)$ were pre-incubated with $10 \mu \mathrm{g} / \mathrm{ml}$ L. pentosus S-PT84 for $24 \mathrm{~h}$. HCT116 or SW480 cells were co-incubated with PBMCs under SFN treatment for $48 \mathrm{~h}$. Cell extracts from (A) HCT116 or (B) SW480 cells were prepared for western blotting as indicated. GAPDH was used as a loading control. (C) Effect of SFN on acetylation of Histone H4 in PBMCs. PBMCs were cultured with or without 5-20 $\mu \mathrm{mol} / 1 \mathrm{SFN}$ for $48 \mathrm{~h}$. Cell extracts from PBMCs were prepared for western blotting as indicated. $\beta$-actin was used as a loading control. The band intensities were quantified with ImageJ software. Band intensities were normalized by (A and B) GAPDH or (C) $\beta$-actin. Fold changes relative to the control (vehicle) lane were calculated. Arrows indicate the cIAP-1 or TNFR1 bands. SFN, Sulforaphane; PBMCs, peripheral blood mononuclear cells; TNFR, tumor necrosis factor receptor; cIAP, cellular inhibitor of apoptosis. 
is a practical approach for the chemoprevention of human malignant tumors (32).

Sulforaphane induces apoptosis in several types of cancer cells (9-13), and Lactobacilli also induce apoptosis in cancer cells by activating immune cells $(25,41)$. We found that sulforaphane enhanced apoptosis in human colon carcinoma cells by co-culture with Lactobacillus-treated PBMCs.

Lactobacillus strains upregulate TRAIL production in human immune cells (25), and sulforaphane induces the expression of DR5, a TRAIL receptor, in human cancer cells $(35,36)$. Therefore, apoptosis induced by a combination of sulforaphane and the Lactobacillus strain L. pentosus S-PT84 may depend on the TRAIL pathway. However, we found that apoptosis was TRAIL-independent because exogenous addition of a soluble human recombinant DR5/Fc chimera, which binds soluble TRAIL and prevents TRAIL binding to its receptor, failed to prevent apoptosis. Furthermore, the concentration of TRAIL in the culture supernatant was low from the combined treatment of sulforaphane and co-culture with Lactobacillus-treated PBMCs (data not shown). Instead, apoptosis was likely caused by TNF $\alpha$ because the TNFR/Fc chimera significantly inhibited apoptosis. Moreover, soluble human recombinant $\mathrm{Fas} / \mathrm{Fc}$ chimera and a granzyme B inhibitor did not attenuate apoptosis by the combination of sulforaphane and co-culture with Lactobacillus-treated PBMCs in HCT116 and SW480 cells. On the other hand, apoptosis was markedly inhibited by zVAD-fmk, a pan-caspase inhibitor, and induced mitochondria membrane depolarization. Sulforaphane induces apoptosis in various tumor cells via a mitochondria-dependent pathway by inducing reactive oxygen species (ROS) (42-44). These results suggest that this combination was dependent on both the extrinsic and intrinsic pathways of apoptosis. Sulforaphane suppresses LPS-induced cell signaling, including TNF $\alpha$ (45), but we found that sulforaphane did not inhibit TNF $\alpha$ production induced by L. pentosus S-PT84 in both cell types. Sulforaphane acts as a histone deacetylase (HDAC) inhibitor $(46,47)$, and several HDAC inhibitors suppress the activities of immune cells (48-50). Therefore, sulforaphane may potentially suppress immune activities by inhibiting HDAC. We investigated the effect of sulforaphane on histone acetylation by western blotting, but acetylation of histone $\mathrm{H} 4$ was not changed by 5 and $10 \mu \mathrm{M}$ sulforaphane in PBMCs.

The expression of cIAP-1 and cIAP-2 was also markedly induced by co-culture with Lactobacillus-treated PBMCs in both cells. The induction of cIAP-1 and cIAP-2 may contribute to the prevention of apoptosis in colon cancer cells in co-culture with Lactobacillus-treated PBMCs despite upregulation of TNF $\alpha$. Interestingly, sulforaphane suppressed the expression of cIAP-1 and cIAP-2 induced by co-culture with Lactobacillus-treated PBMCs. Sulforaphane downregulates cIAP-1 and cIAP-2 in human prostate cancer cells (14). Proteins in the IAP family are widely and highly expressed in many cancers and are an important target for anticancer therapy (51).

We found that sulforaphane enhanced apoptosis in human colon cancer cells under co-culture with Lactobacillus-treated PBMCs. Production of TNF $\alpha$ from PBMCs was induced by co-culture with Lactobacillus, and sulforaphane suppressed the expression of cIAP-1 and cIAP-2 in colon cancer cells. Furthermore, to verify the preventive effect of the combination for colon carcinogenesis, the verification by long-term experiments with exposure to an exogenous chemical carcinogen are needed.

Sulforaphane and Lactobacillus are contained in a wide variety of foods; therefore, consumption of sulforaphane and Lactobacillus may have a protective effect against colon cancer.

\section{Acknowledgements}

The authors would like to thank Mr. Takashi Yasuda, Dr Hiroyuki Hoshiko, Dr Takeshi Kanamori and Dr Keiichi Abe (Research Institute, Suntory Global Innovation Center) for supplying Lactobacillus pentosus S-PT84 and their insightful comments and suggestions.

\section{Funding}

The present study was supported in part by JSPS KAKENHI (grant. no. JP25860466) and by a grant from the Suntory Co., Japan (grant. no. J142001069).

\section{Availability of data and materials}

The datasets used and/or analyzed during the current study are available from the corresponding author on reasonable request.

\section{Authors' contributions}

SY, MH and TS conceived and designed the study, and wrote the manuscript. SY and MH conducted the experiments, and performed the data analysis. All authors read and approved the final manuscript.

\section{Ethics approval and consent to participate}

PBMCs were acquired from healthy volunteers after obtaining written informed consent. The present study was approved by the Kyoto Prefectural University of Medicine Research Ethics Committee (permission. no. RBMR-C-919).

\section{Patient consent for publication}

Not applicable.

\section{Competing interests}

Toshiyuki Sakai received funding from Suntory Co. (Japan) who also supplied the Lactobacillus pentosus strain S-PT84 used in the study.

\section{References}

1. Bray F, Ferlay J, Soerjomataram I, Siegel RL, Torre LA, and Jemal A: Global cancer statistics 2018: GLOBOCAN estimates of incidence and mortality worldwide for 36 cancers in 185 countries. CA Cancer J Clin 68: 394-424, 2018.

2. Terry P, Giovannucci E, Michels KB, Bergkvist L, Hansen H, Holmberg L and Wolk A: Fruit, vegetables, dietary fiber, and risk of colorectal cancer. J Natl Cancer Inst 93: 525-533, 2001.

3. Sato Y, Tsubono Y, Nakaya N, Ogawa K, Kurashima K, Kuriyama S, Hazawa A, Nishino Y, Shibuya D and Tsuji I: Fruit and vegetable consumption and risk of colorectal cancer in Japan: The Miyagi Cohort Study. Public Health Nutr 8: 309-314, 2005. 
4. Aoyama N, Kawado M, Yamada H, Hashimoto S, Suzuki K, Wakai K, Suuki S, Watanabe Y and Tamakoshi A: Low intake of vegetables and fruits and risk of colorectal cancer: The Japan collaborative cohort study. J Epidemiol 24: 353-360, 2014.

5. Shemesh N and Arber N: Curcumin alone and in combination for prevention of colorectal cancer. Curr Colorectal Cancer Rep 10: 62-67, 2014.

6. Sharmila G, Bhat FA, Arunkumar R, Elumalai P, Raja Singh P, Senthilkumar K and Arunakaran J: Chemopreventive effect of quercetin, a natural dietary flavonoid on prostate cancer in in vivo model. Clin Nutr 33: 718-726, 2014.

7. Ullah MF, Bhat SH, Husain E, Abu-Duhier F, Hadi SM, Sarkar FH and Ahmad A: Cancer chemopreventive pharmacology of phytochemicals derived from plants of dietary and non-dietary origin: Implication for alternative and complementary approaches. Phytochem Rev 13: 811-833, 2014.

8. Zhang Y, Talalay P, Cho CG and Posner GH: A major inducer of anticarcinogenic protective enzymes from broccoli: Isolation and elucidation of structure. Proc Natl Acad Sci USA 89: 2399-2403, 1992.

9. Fahey JW, Zhang Y and Talalay P: Broccoli sprouts: An exceptionally rich source of inducers of enzymes that protect against chemical carcinogens. Proc Natl Acad Sci USA 94: 10367-10372, 1997.

10. Gamet-Payrastre L, Li P, Lumeau S, Cassar G, Dupont MA, Chevolleau S, Gasc N, Tulliez J and Terce F: Sulforaphane, a naturally occurring isothiocyanate, induces cell cycle arrest and apoptosis in HT29 human colon cancer cells. Cancer Res 60: 1426-1433, 2000.

11. Singh AV, Xiao D, Lew KL, Dhir R and Singh SV: Sulforaphane induces caspase-mediated apoptosis in cultured PC-3 human prostate cancer cells and retards growth of PC-3 xenografts in vivo. Carcinogenesis 25: 83-90, 2004.

12. Pledgie-Tracy A, Sobolewski MD and Davidson NE: Sulforaphane induces cell type-specific apoptosis in human breast cancer cell lines. Mol Cancer Ther 6: 1013-1021, 2007.

13. Singh SV, Srivastava SK, Choi S, Lew KL, Antosiewicz J, Xiao D, Zeng Y, Watkins SC, Johnson CS, Trump DL, et al: Sulforaphane-induced cell death in human prostate cancer cells is initiated by reactive oxygen species. J Biol Chem 280 : 19911-19924, 2005.

14. Choi S, Lew KL, Xiao H, Herman-Antosiewicz A, Xiao D, Brown CK and Singh SV: D,L-Sulforaphane-induced cell death in human prostate cancer cells is regulated by inhibitor of apoptosis family proteins and Apaf-1. Carcinogenesis 28: 151-162, 2007.

15. Fimognari $C$ and Hrelia $P$ : Sulforaphane as a promising molecule for fighting cancer. Mutat Res 635: 90-104, 2007.

16. Myzak MC and Dashwood RH: Chemoprotection by sulforaphane: Keep one eye beyond Keap1. Cancer Lett 233: 208-218, 2006.

17. Clarke JD, Dashwood RH and Ho E: Multi-targeted prevention of cancer by sulforaphane. Cancer Lett 269: 291-304, 2008.

18. Juge N, Mithen RF and Traka M: Molecular basis for chemoprevention by sulforaphane: A comprehensive review. Cell Mol Life Sci 64: 1105-1127, 2007.

19. Yeh CT and Yen GC: Effect of sulforaphane on metallothionein expression and induction of apoptosis in human hepatoma HepG2 cells. Carcinogenesis 26: 2138-2148, 2005.

20. Takeda K and Okumura K: Effects of a fermented milk drink containing Lactobacillus casei strain Shirota on the human NK-cell activity. J Nutr 137 (3 Suppl 2): S791-S793, 2007.

21. Takagi A, Matsuzaki T, Sato M, Nomoto K, Morotomi M and Yokokura T: Inhibitory effect of oral administration of Lactobacillus casei on 3-methylcholanthrene-induced carcinogenesis in mice. Med Microbiol Immunol 188: 111-116, 1999.

22. de Moreno de LeBlanc A, Matar C, LeBlanc N and Perdigón G: Effects of milk fermented by Lactobacillus helveticus R389 on a murine breast cancer model. Breast Cancer Res 7: R477-R486, 2005

23. Orland A, Linsalata M and Russo F: Antiproliferative effects on colon adenocarcinoma cells induced by co-administration of vitamin $\mathrm{K} 1$ and Lactobacillus rhamnosus GG. Int J Oncol 48 : 2629-2638, 2016

24. Ishikawa H,Akedo I, Otani T,Suzuki T, Nakamura T, Takeyama I, Ishiguro S, Miyaoka E, Sobue T and Kakizoe T: Randomized trial of dietary fiber and Lactobacillus casei administration for prevention of colorectal tumors. Int J Cancer 116: 762-767, 2005

25. Horinaka M, Yoshida T, Kishi A, Akatani K, Yausda T, Kouhara J, Wakada M and Sakai T: Lactobacillus strains induce TRAIL production and facilitate natural killer activity against cancer cells. FEBS Lett 584: 577-582, 2010.
26. Haller D, Bode C, Hammes WP, Pfeifer AM, Schiffrin EJ and Blum S: Non-pathogenic bacteria elicit a differential cytokine response by intestinal epithelial cell/leucocyte co-cultures. Gut 47: 79-87, 2000.

27. Donkor ON, Ravikumar M, Proudfoot O, Day SL, Apostolopoulos V, Pukovics G, Vasiljevic T, Nutt SL and Gill H: Cytokine profile and induction of T helper type 17 and regulatory $\mathrm{T}$ cells by human peripheral mononuclear cells after microbial exposure. Clin Exp Immunol 167: 282-295, 2012.

28. Izumo T, Maekawa T, Ida M, Noguchi A, Kitagawa Y, Shibata H, Yasui $\mathrm{H}$ and Kiso $\mathrm{Y}$ : Effect of intranasal administration of Lactobacillus pentosus S-PT84 on influenza virus infection in mice. Int Immunopharmacol 10: 1101-1106, 2010.

29. Izumo T, Izumi F, Nakagawa I, Kitagawa Y, Shibata $H$ and Kiso Y: Influence of Lactobacillus pentosus S-PT84 ingestion on the mucosal immunity of healthy and Salmonella Typhimurium-infected mice. Biosci Microflora 30: 27-35, 2011.

30. Hayama K, Ishijima S, Ono Y, Izumo T, Ida M, Shibata H and Abe S: Protective activity of S-PT84, a heat-killed preparation of Lactobacillus pentosus, against oral and gastric candidiasis in an experimental murine model. Med Mycol J 55: 123-129, 2014 (In Japanese)

31. Izumo T, Maekawa T, Ida M, Kishi A, Akatani K, Kitagawa Y and Kiso Y: Effect of Lactobacillus pentosus S-PT84 ingestion on IFN- $\alpha$ production from plasmacytoid dendritic cells by virus stimulation. Biosci Biotechnol Biochem 75: 370-372, 2011.

32. Yoshida T, Horinaka M and Sakai T: 'Combination-oriented molecular-targeting prevention' of cancer: A model involving the combination of TRAIL and a DR5 inducer. Environ Health Prev Med 15: 203-210, 2010.

33. Cheung KL, Khor TO and Kong AN: Synergistic effect of combination of phenethyl isothiocyanate and sulforaphane or curcumin and sulforaphane in the inhibition of inflammation. Pharm Res 26: 224-231, 2009.

34. Nair S, Hebbar V, Shen G, Gopalakrishnan A, Khor TO, Yu S, $\mathrm{Xu} \mathrm{C}$ and Kong AN: Synergistic effects of a combination of dietary factors sulforaphane and (-) epigallocatechin-3-gallate in HT-29 AP-1 human colon carcinoma cells. Pharm Res 25: 387-399, 2008

35. Matsui T, Sowa Y, Yoshida T, Murata H, Horinaka M, Wakada M, Nakanishi R, Sakabe T, Kubo T and Sakai T: Sulforaphane enhances TRAIL-induced apoptosis through the induction of DR5 expression in human osteosarcoma cells. Carcinogenesis 27: $1768-1777,2006$

36. Shankar S, Ganapathy S and Srivastava RK: Sulforaphane enhances the therapeutic potential of TRAIL in prostate cancer orthotopic model through regulation of apoptosis, metastasis, and angiogenesis. Clin Cancer Res 14: 6855-6866, 2008.

37. Nonaka Y, Izumo T, Izumi F, Maekawa T, Shibata H, Nakano A, Kishi A, Akatani K and Kiso Y: Antiallergic effects of Lactobacillus pentosus strain S-PT84 mediated by modulation of Th1/Th2 immunobalance and induction of IL-10 production. Int Arch Allergy Immunol 145: 249-257, 2008

38. Nagata S: Apoptosis by death factor. Cell 88: 355-365, 1997.

39. Vermijlen D, Froelich CJ, Luo D, Suarez-Huerta N, Robaye B and Wisse E: Perforin and granzyme B induce apoptosis in FasL-resistant colon carcinoma cells. Cancer Immunol Immunother 50: 212-217, 2001.

40. Trapani JA and Smyth MJ: Functional significance of the perforin/granzyme cell death pathway. Nat Rev Immunol 2: 735-747, 2002.

41. Rachid M, Matar C, Duarte J and Perdigon G: Effect of milk fermented with a Lactobacillus helveticus $\mathrm{R} 389(+)$ proteolytic strain on the immune system and on the growth of 4T1 breast cancer cells in mice. FEMS Immunol Med Microbiol 47 242-253, 2006

42. Choi WY, Choi BT, Lee WH and Choi YH: Sulforaphane generates reactive oxygen species leading to mitochondrial perturbation for apoptosis in human leukemia U937 cells. Biomed Pharmacother 62: 637-644, 2008.

43. Jo GH, Kim GY, Kim WJ, Park KY and Choi YH: Sulforaphane induces apoptosis in T24 human urinary bladder cancer cells through a reactive oxygen species-mediated mitochondrial pathway: The involvement of endoplasmic reticulum stress and the Nrf2 signaling pathway. Int J Oncol 45: 1497-1506, 2014

44. Park HS, Han MH, Kim GY, Moon SK, Kim WJ, Hwang HJ, Park KY and Choi YH: Sulforaphane induces reactive oxygen species-mediated mitotic arrest and subsequent apoptosis in human bladder cancer 5637 cells. Food Chem Toxicol 64: $157-165,2014$. 
45. Folkard DL, Melchini A, Traka MH, Al-Bakheit A, Saha S Mulholland F, Watson A and Mithen RF: Suppression of LPS-induced transcription and cytokine secretion by the dietary isothiocyanate sulforaphane. Mol Nutr Food Res 58: 2286-2296, 2014.

46. Myzak MC, Karplus PA, Chung FL and Dashwood RH: A novel mechanism of chemoprotection by sulforaphane: Inhibition of histone deacetylase. Cancer Res 64: 5767-5774, 2004.

47. Dashwood RH, Myzak MC and Ho E: Dietary HDAC inhibitors: Time to rethink weak ligands in cancer chemoprevention? Carcinogenesis 27: 344-349, 2006.

48. Leoni F, Zaliani A, Bertolini G, Porro G, Pagani P, Pozzi P, Donà G, Fossati G, Sozzani S, Azam T, et al: The antitumor histone deacetylase inhibitor suberoylanilide hydroxamic acid exhibits antiinflammatory properties via suppression of cytokines. Proc Natl Acad Sci USA 99: 2995-3000, 2002.
49. Leoni F, Fossati G, Lewis EC, Lee JK, Porro G, Pagani P, Modena D, Moras ML, Pozzi P, Reznikov LL, et al: The histone deacetylase inhibitor ITF2357 reduces production of pro-inflammatory cytokines in vitro and systemic inflammation in vivo. Mol Med 11: 1-15, 2005.

50. Bridle BW, Chen L, Lemay CG, Diallo JS, Pol J, Nguyen A, Capretta A, He R, Bramson JL, Bell JC, et al: HDAC inhibition suppresses primary immune responses, enhances secondary immune responses, and abrogates autoimmunity during tumor immunotherapy. Mol Ther 21: 887-894, 2013.

51. Saleem M, Qadir MI, Perveen N, Ahmad B, Saleem U, Irshad T and Ahmad B: Inhibitors of apoptotic proteins: New targets for anticancer therapy. Chem Biol Drug Des 82: 243-251, 2013. 